\title{
Berlin aims to create research powerhouse
}

German government finds a creative way to fund universities.

\section{BY QUIRIN SCHIERMEIER}

“B erlin is poor but sexy," Klaus Wowereit once famously said of Germany's capital, where he has served as mayor since 2001. Now he is hoping that more money will buy it a little extra love, at least from biomedical researchers. Last week, he proudly announced an opulent deal to boost the city's scattered health-research base, sweetened with a hefty chunk of federal funding. Those in charge of the new Berlin Institute of Health (BIH) that was created by the deal believe that it could rival research powerhouses in the United States and Britain.

It also offers a model for circumventing the country's long-standing restrictions on federal funding of universities, a rule that baffles many outsiders. "That's the way forward, no matter what critics might say," says Wolfgang Herrmann, president of the Technical University of Munich, one of Germany's highest-ranked research universities.

The BIH will ally the Charité, Berlin's largest university clinic, with the Max Delbrück Center for Molecular Medicine (MDC), a national biomedical research centre. Over the next five years, the institute will receive more than $€ 300$ million (US\$ $\$ 380$ million) in extra funding, $90 \%$ of which will come from federal budgets, with the remainder coming from the city and private sources. From 2018 onwards, the federal government will permanently support the BIH with an annual sum of $€ 80$ million. "That's a marvellous windfall," says Walter Rosenthal, the MDC's scientific director. "It could help us set up in Berlin something equivalent to the Howard Hughes Medical Institute in Maryland - it's a once-ina-lifetime opportunity."

The MDC researches basic molecular medicine, but has little direct access to patients, so teaming up with the Charite should help to speed its discoveries to the clinic. Under the auspices of the BIH, molecular biologists and clinical researchers will join forces to tackle a spectrum of illnesses, from cancer to cardiovascular disorders, and neurodegenerative diseases such as Parkinson's and Alzheimer's. The $\mathrm{BIH}$ will complement Germany's six national health-research centres, which have narrower focuses. Work at the new institute, spread across Berlin's health campuses, could start next spring. Research coordinators at the Charité and the MDC have put together a preliminary research plan, which an international evaluation team will review by March 2013.

A significant portion of the start-up cash, says Rosenthal, will be used to equip BIH groups with state-of-the art sequencing, mass spectroscopy and bio-imaging technologies, and to expand the MDC's bioinformatics capacity. The newly equipped labs and secure long-term funding should lure biomedical researchers from around the world. Over the next 8 years, up to 60 collaborative groups could be set up, Rosenthal says.

"Recruitment is the bottleneck when it comes to turning Berlin into a health-science hub of truly international rank," says Claus Scheidereit, an oncologist who coordinates cancer research at the MDC. "If we can get over that, we can start to think really big."

The BIH is the German government's latest attempt to inject national funds into universities, circumventing a highly federalized system in which state governments jealously guard their responsibility for universities. The gov-

"It could help us 'ernment's acclaimed set up in Berlin for example, invited something German universiequivalent to ties to compete for the Howard federal top-up grants Hughes Medical and has so far genInstitute." erated thousands of new science jobs. Collaborations that resemble the BIH, linking national research centres and universities, have also been forged in Karlsruhe, and between Jülich and Aachen.

A proposed amendment to Germany's constitutional law would allow the federal government to co-finance universities permanently, but it is unlikely to win the required two-thirds majority in parliament. Its opponents fear that the bill would allow Berlin to dictate national policy in areas, particularly secondary education, in which the states enjoy near-total control.

Scientists maintain that Germany's federalized university system is hampering the creation of national research hubs such as those in neighbouring Switzerland. "Why shouldn't the Technical University of Munich become Germany's federal institute of technology?" says Herrmann. "Because the rules don't allow it? If it helps our country, we should change them sooner rather than later." - 